Muséologies

Les cahiers d'études supérieures

muséologies

\title{
Portfolio de l'installation Exodus 2048 : Van Abbemuseum, Eindhoven, Pays-Bas, 2008 ; New Museum, New York, 2009
}

\section{Michael Blum}

Volume 9, numéro 1, 2018

Monde des Arts / Arts des mondes

URI : https://id.erudit.org/iderudit/1052633ar

DOI : https://doi.org/10.7202/1052633ar

Aller au sommaire du numéro

Éditeur(s)

Association Québécoise de Promotion des Recherches Étudiantes en

Muséologie (AQPREM)

ISSN

1718-5181 (imprimé)

1929-7815 (numérique)

Découvrir la revue

Citer ce compte rendu

Blum, M. (2018). Compte rendu de [Portfolio de l'installation Exodus 2048 : Van

Abbemuseum, Eindhoven, Pays-Bas, 2008 ; New Museum, New York, 2009].

Muséologies, 9(1), 163-171. https://doi.org/10.7202/1052633ar

Tous droits réservés ( $\subset$ Association Québécoise de Promotion des Recherches Étudiantes en Muséologie (AQPREM), 2018
Ce document est protégé par la loi sur le droit d'auteur. L'utilisation des services d'Érudit (y compris la reproduction) est assujettie à sa politique d'utilisation que vous pouvez consulter en ligne.

https://apropos.erudit.org/fr/usagers/politique-dutilisation/ 
Carnet trois

\section{Portfolio de l'installation Exodus 2048: Van Abbemuseum, Eindhoven, Pays- Bas, 2008; New Museum, New York, 2009.}

Michael Blum parfois sans réellement être reliés les uns aux autres. 
Dans l'installation Exodus 2048, Michael Blum imagine un futur dans lequel la population palestinienne a repris le contrôle d'Israël suite à des changements politiques et économiques mondiaux résultant dans le retrait du soutien des Etats-Unis envers le pays. Forcée à un nouvel exil un siècle après la création de l'état d'Israël, la population israélienne trouve refuge aux Etats-Unis ou ailleurs. C'est l'histoire d'un groupe de réfugiés arrivant aux Pays-Bas, rappelant celle de l'Exodus 1947, que l'artiste créé en 2008 au Van Abbemuseum à Eindhoven aux Pays-Bas puis, en 2009, au New Museum de New York. En mettant en dialogue ces deux moments de l'installation faisant écho aux deux moments du récit, l'artiste rappelle avec humour et distance les aléas de ces mondes de l'art, qui, même étant situés en Occident, se chevauchent parfois sans réellement être reliés les uns aux autres. 


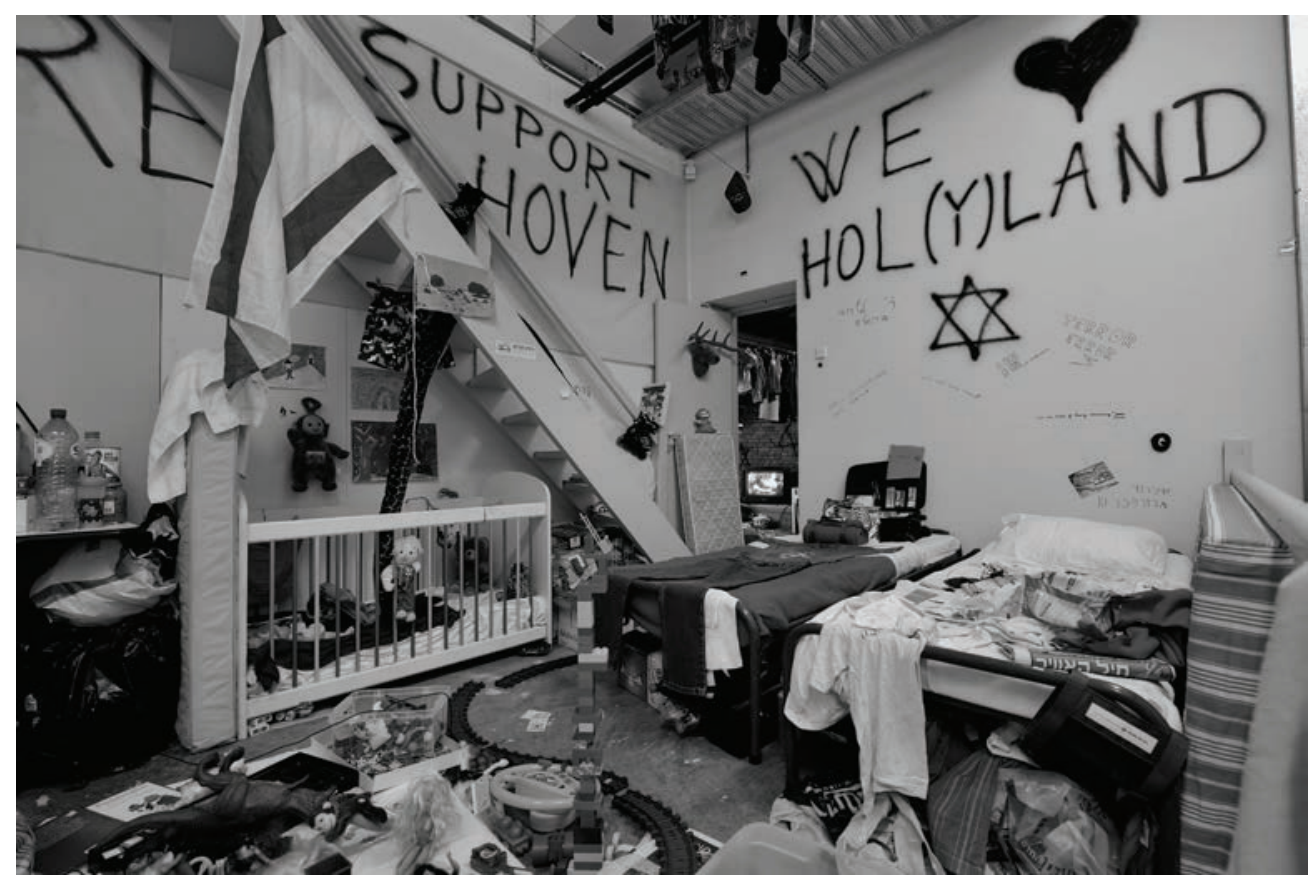

Michael Blum, "Exodus 2048", Van Abbemuseum, Eindhoven, 2008.

Photo Peter Cox. Courtesy of the artist. 


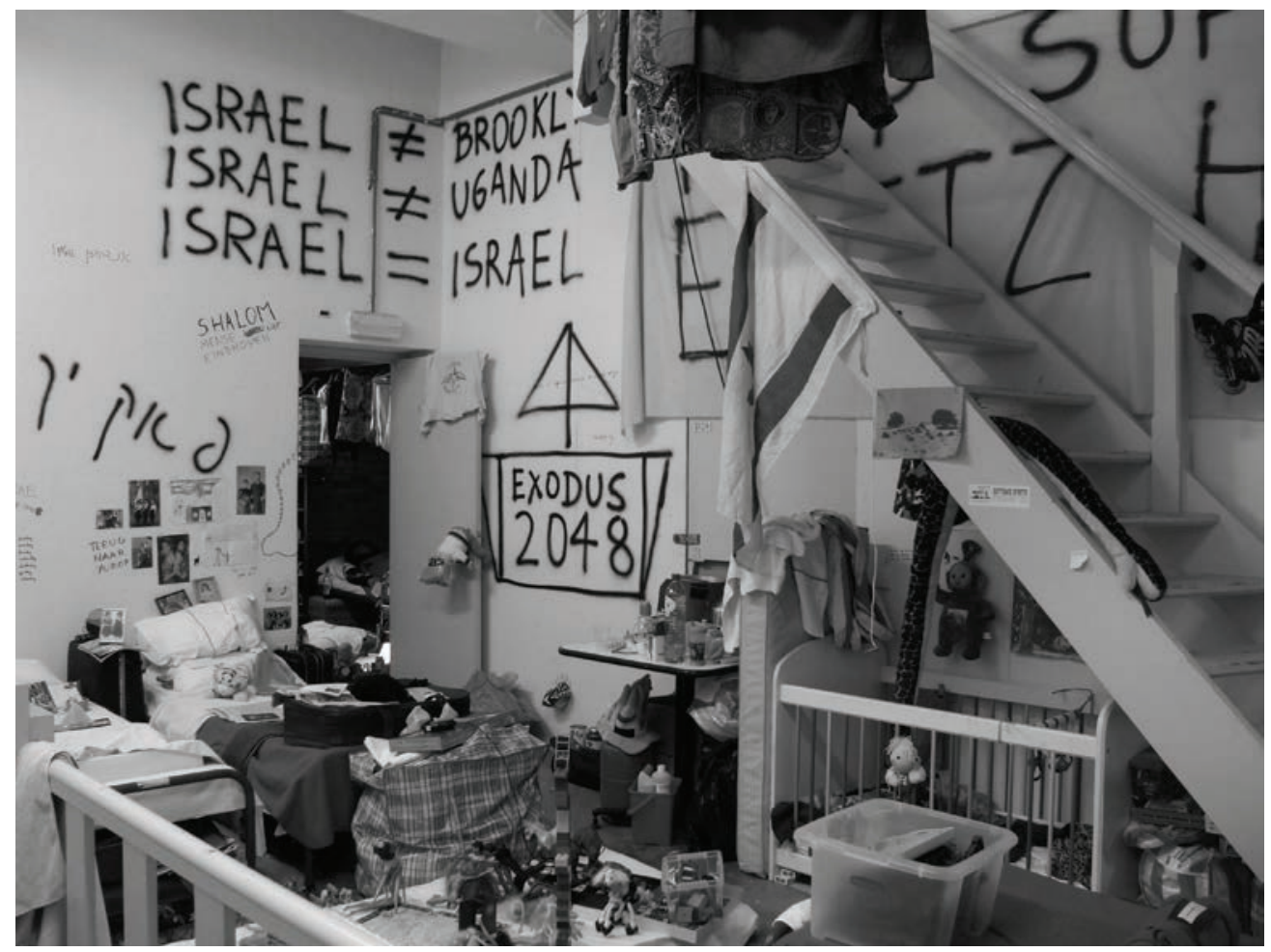

Michael Blum, "Exodus 2048", Van Abbemuseum, Eindhoven, 2008. Photo Michael Blum. Courtesy of the artist. 


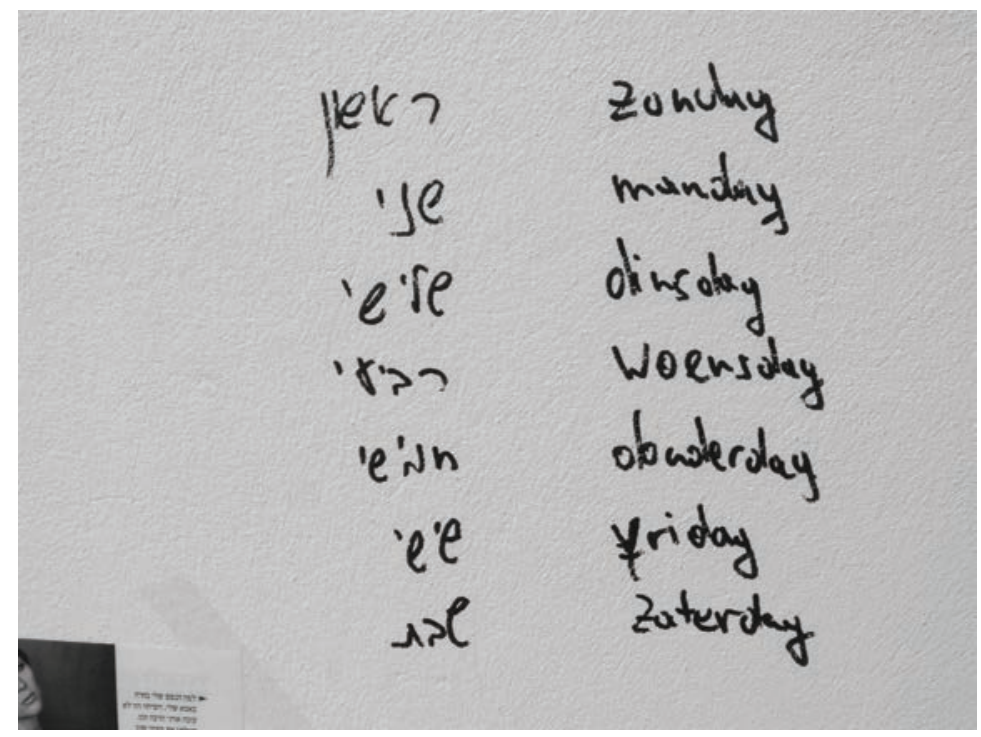

Michael Blum, "Exodus 2048", Van Abbemuseum, Eindhoven, 2008. Photo Michael Blum. Courtesy of the artist.

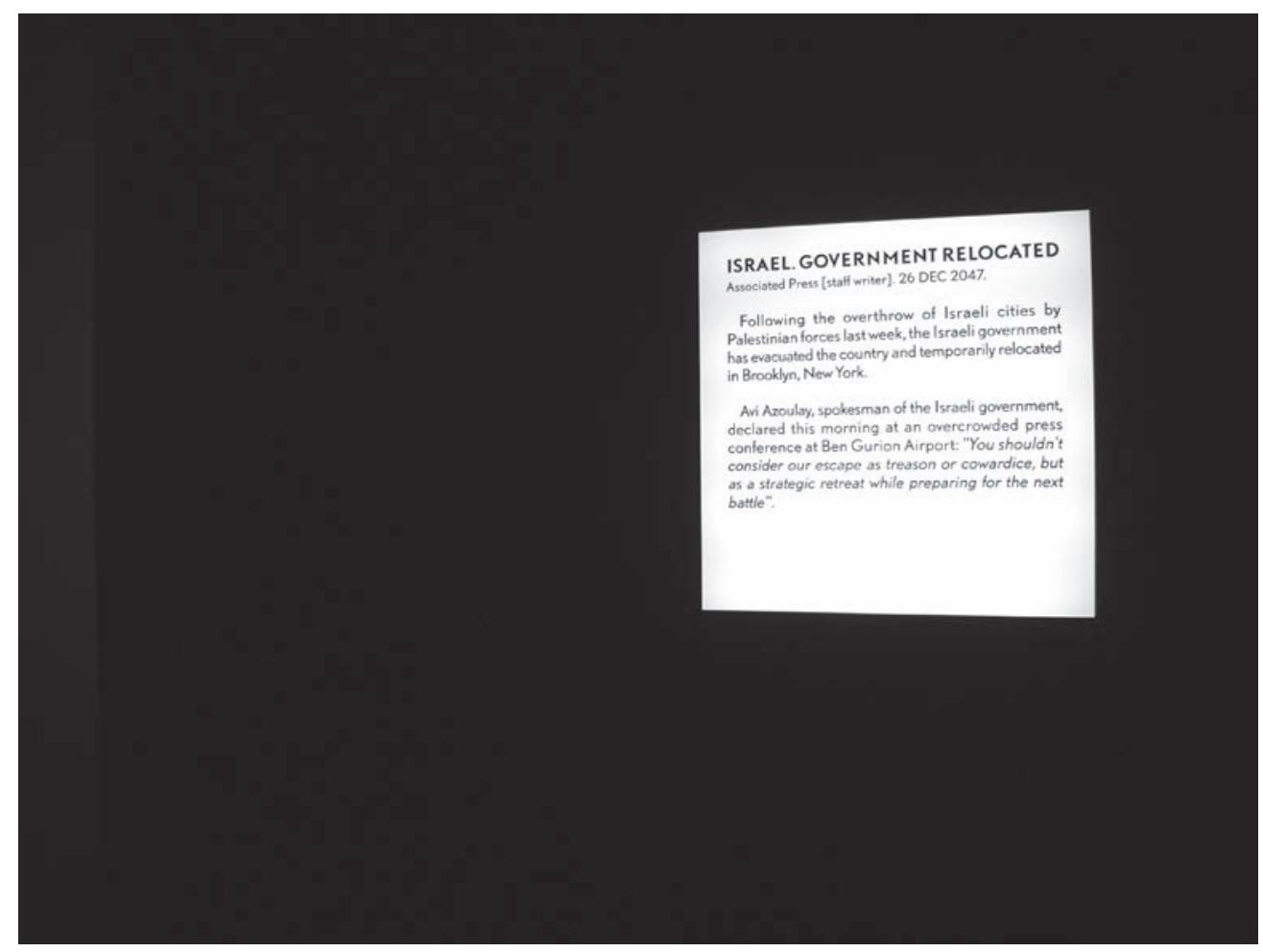

Michael Blum, "Exodus 2048", Van Abbemuseum, Eindhoven, 2008. Photo Michael Blum. Courtesy of the artist. 


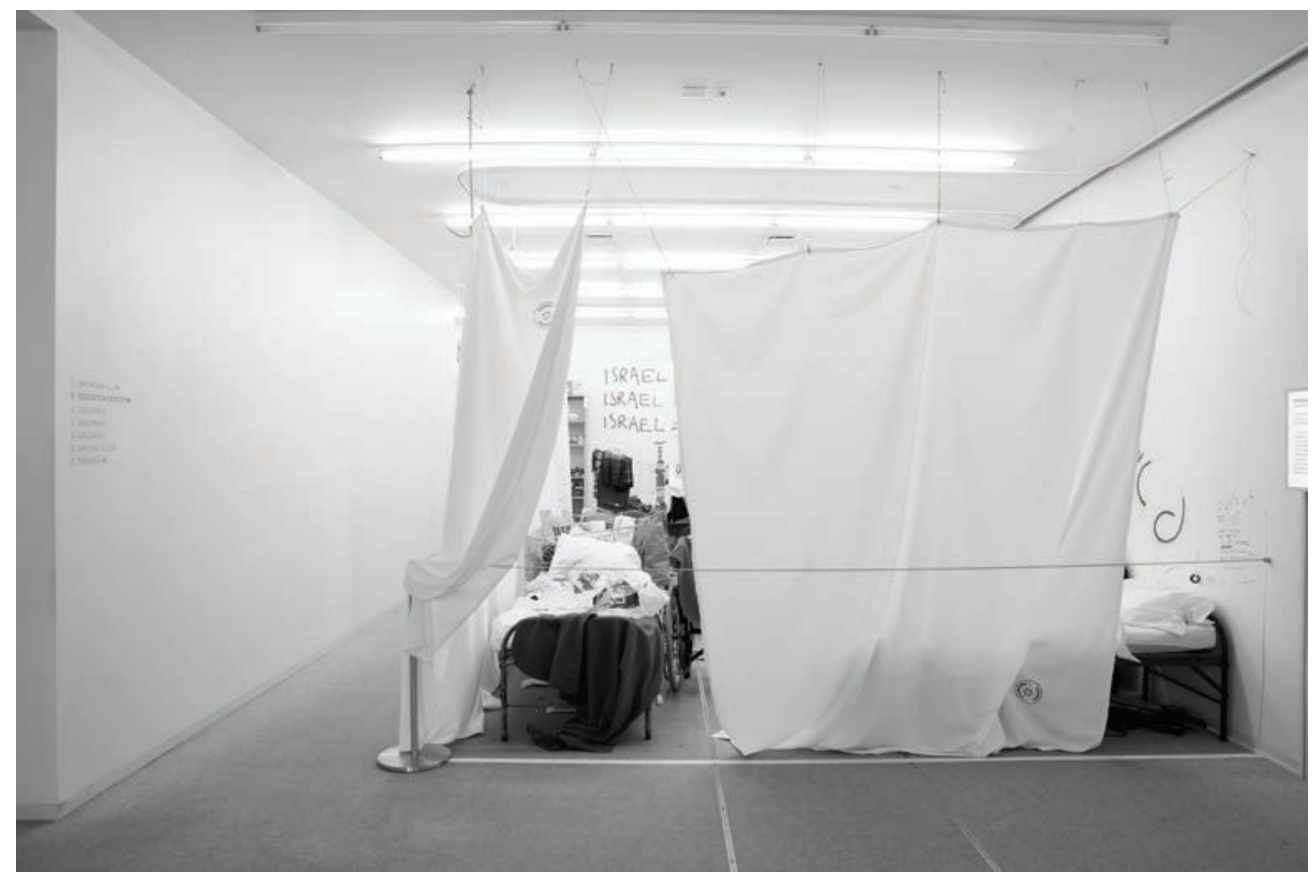

Michael Blum, "Exodus 2048”, New Museum, New York, 2009. Photo Benoît Pailley. Courtesy of the artist. 


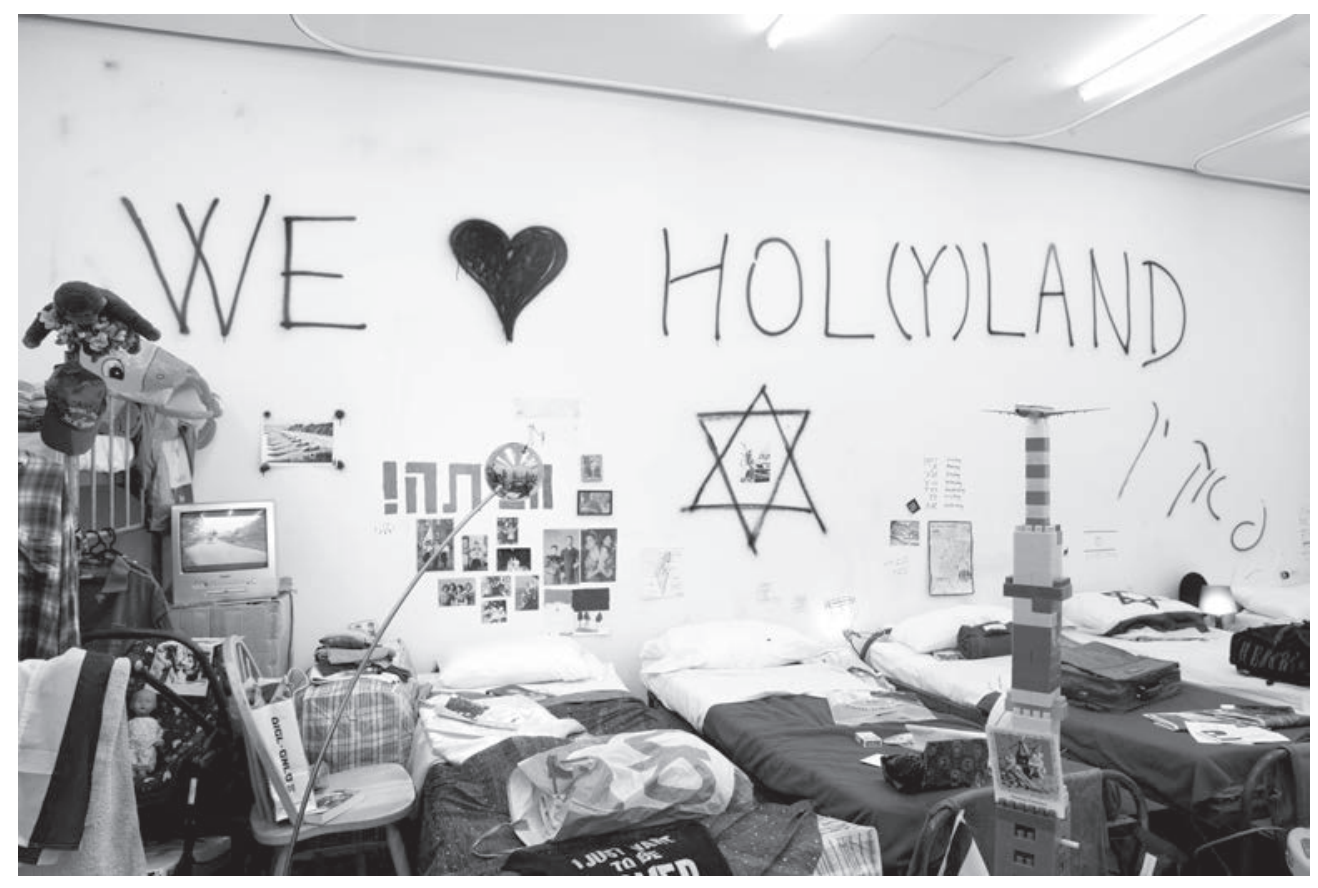

Michael Blum, "Exodus 2048”, New Museum, New York, 2009. Photo Benoît Pailley.

Courtesy of the artist. 
Nine

S.f.

81) 1 (f)

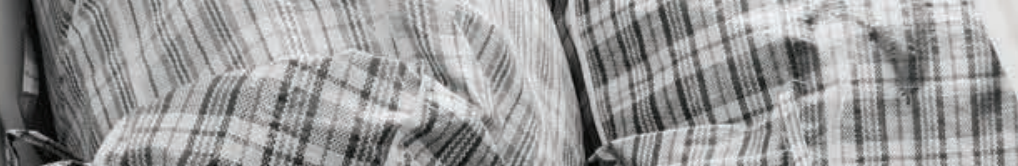

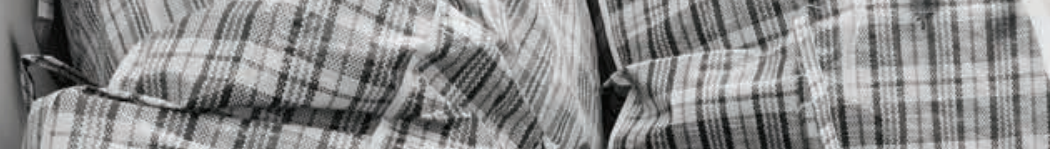

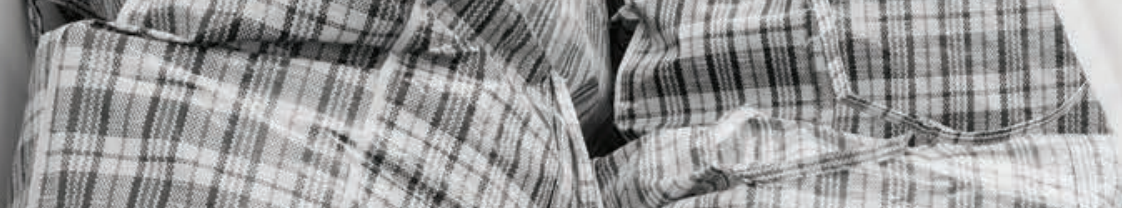

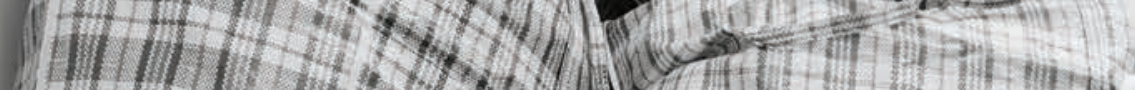

H. If
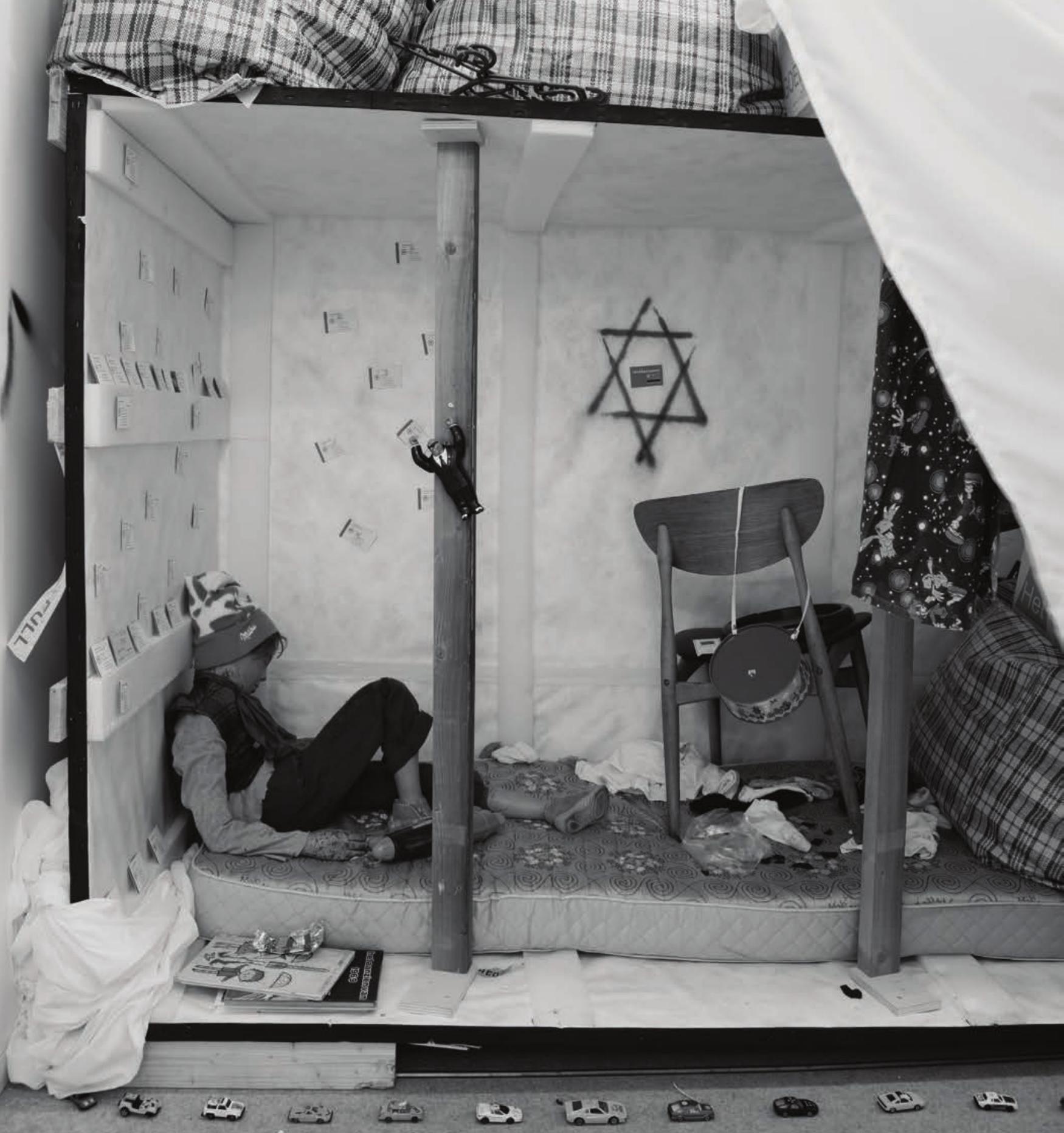


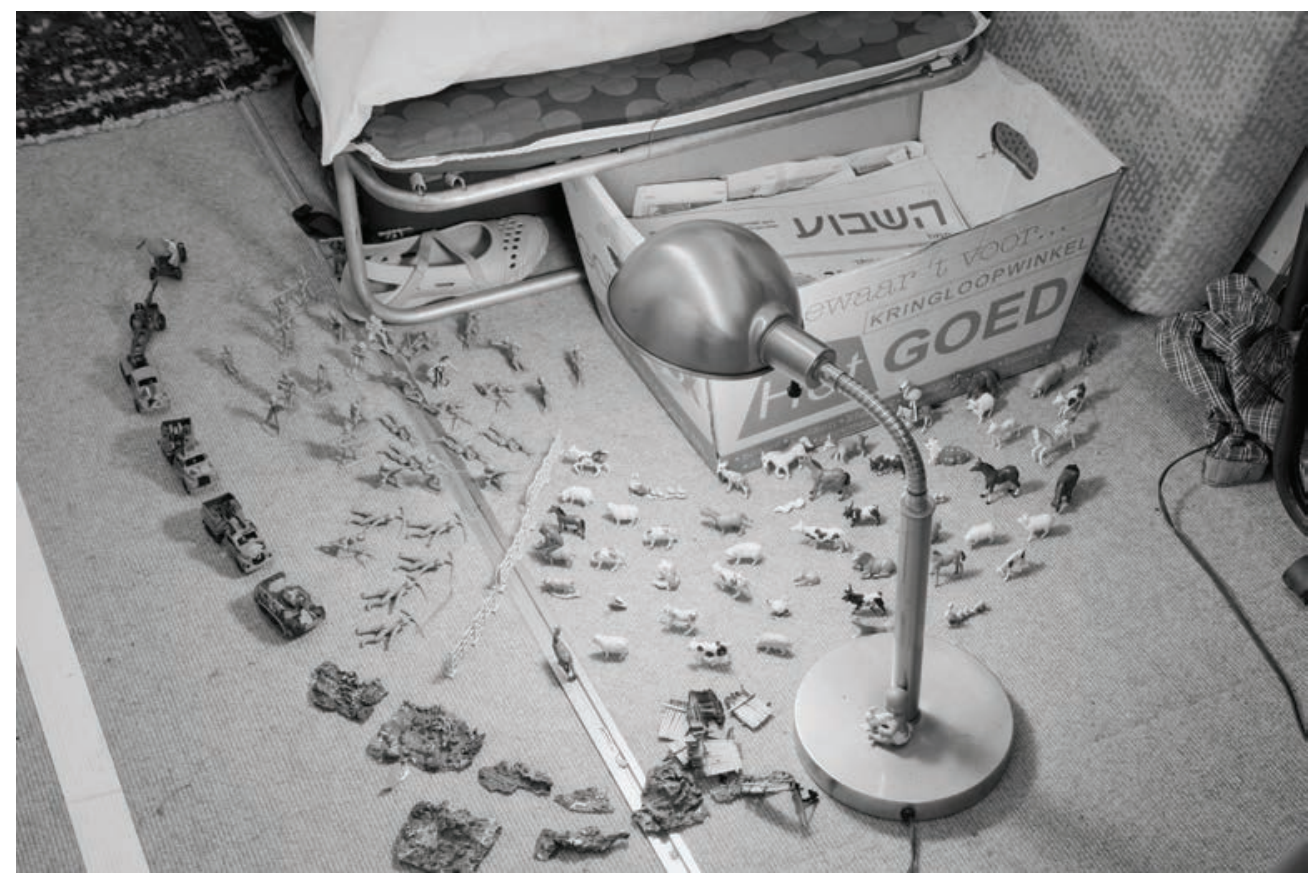

Michael Blum, "Exodus 2048”, New Museum, New York, 2009. Photo Benoît Pailley.

Courtesy of the artist. 